\title{
ANÁLISE MORFOMÉTRICA DA MICROBACIA HIDROGRÁFICA DO CÓRREGO MANOEL JOÃO, PORTO NACIONAL (TO)
}

\section{Lucas Lima Moreira' ${ }^{1}$ Ricardo Ribeiro Dias ${ }^{2}$}

(1 - Universidade Federal do Tocantins, discente do curso de Engenharia Ambiental,lucas.1m@hotmail.com; 2 - Universidade Federal do Tocantins, docente do curso de Engenharia Ambiental, ricdias@uft.edu.br)

Resumo: O presente estudo teve por objetivo caracterizar a morfometria da bacia do córrego Manoel João. Os parâmetros avaliados foram Ordem da bacia, Comprimento do rio principal, Gradiente de Canais (Gc), Área da bacia (A), Índice de circularidade (Ic), Densidade de rios (Dr), Densidade de drenagem (Dd), Coeficiente de Manutenção $(\mathrm{Cm})$, Amplitude altimétrica máxima $(\mathrm{Hm})$ e Relação de relevo $(\mathrm{Rr})$. Foram utilizados como base de dados o MDE disponibilizado pelo projeto TOPODATA, a base cartográfica digital contínua da Seplan/TO, e dados do levantamento de uso e cobertura do solo realizado por Santos (2015) na mesma área de estudo. Os dados foram processados e analisados por meio dos softwares Google Earth eArcGIS. De acordo com os resultados a bacia é de $3^{\mathrm{a}}$ ordem, conforme Strahler, e possui área inferior a $100 \mathrm{~km}^{2}$, refletindo diretamente os efeitos do uso da terra. Os valores de $\mathrm{Dd}$, Dr e Cm evidenciam um sistema de drenagem pouco desenvolvido. A Rr e declividade expressam relevo suave ondulado, e o valor de Ic atribui à bacia forma alongada, com menor risco de ocorrência de enchentes.

Palavras-chave:Hidrologia. Manejo de bacias.Planejamento ambiental.

\section{MORPHOMETRIC ANALYSIS OF THE BASIN IN RIVER MANOEL JOÃO, PORTO NACIONAL (BRAZIL)}

Abstract: This study aimed to characterize the morphometrythe basin of ManoelJoão stream. The parameters used were the basin order, the main river length, the channel gradient $(\mathrm{Gc})$, the basin area (A), the Circularity index (Ci), the Density of rivers (Dr), the Drainage density $(\mathrm{Dd})$, the Maintenance coefficient $(\mathrm{Cm})$, the Maximum altimetry amplitude $(\mathrm{Hm})$ and the Relief ratio (Rr). The data used in this work was taken from the MDE database provided by TOPODATA design, Seplan-TO continuous digital cartographic base, and the use and land 
cover data collection done by Santos (2015) in the same area of study. The data was processed and analyzed via Google Earth and ArcGIS software. According to the results this is a $3^{\text {rd }}$ order basin, according to Strahler, and it has an area inferior to 100 square kilometers which reflects directly the land use effects. The values of $\mathrm{Dd}$, Dr and $\mathrm{Cm}$ show an underdeveloped drainage system. The $\mathrm{Rr}$ and declivity express undulated relief, and the value of $\mathrm{Ci}$ attributes to the basin an elongated shape, representing a lower risk of flooding.

Keywords: Hydrology, Watershed management, Environmental planning.

\section{ESTUDIO MORFOMÉTRICO DE LA CUENCA DEL ARROYO MANOEL JOÃO, PORTO NACIONAL (BRASIL)}

Resumen: Este estudio tuvo como objetivo caracterizar la morfometria de la cuenca del arroyo Manoel João. Los parámetros utilizados fueron el Orden de la cuenca, la longitud del río principal, el canal de gradiente (Gc), área de la cuenca (A), índice de circularidad (Ic), Densidad de ríos (Dr), densidad de drenaje (Dd), coeficiente de Mantenimiento $(\mathrm{Cm})$, la amplitud máxima de altimetría $(\mathrm{Hm})$ y la relación de desahogo $(\mathrm{Rr})$. Se utilizaron como base de datos de la MDE proporcionada por el proyecto TOPODATA, continua base cartográfica digital de Seplan-TO, y el uso de los datos de la encuesta y la ocupación del suelo hechas porSantos (2015) en la misma área de estudio. Los datos fueron procesados y analizados mediante el software de Google Earth y ArcGIS. De acuerdo con los resultados, la cuenca es de 3er orden como Strahler, y tiene una superficie de menos de 100 kilómetros cuadrados, lo que refleja directamente los efectos de la utilización del suelo. Los valores Dd, Dr y $\mathrm{Cm}$ muestran un sistema de drenaje con poco desarrollo. El $\mathrm{Rr}$ y la inclinación expresan ondulaban alivio, y el valor de Ic se inserta en un tazón forma ondulada, con un menor riesgo de inundación

Palabras clave: Hidrología. El manejo de cuencas. Planificación ambiental.

\section{Introdução}

O monitoramento de dados relativos a uma bacia hidrográfica permite a realização de uma avaliação a respeito dos recursos hídricos, que se apropriada, permite propor adequações quanto ao uso e ocupação do solo, levando assim a um manejo sustentável dos recursos naturais envolvidos (CAMPOS et al., 2015).

Estudos morfométricos constituem-se como ferramenta fundamental para $\mathrm{o}$ entendimento da dinâmica hídrica e para o planejamento ambiental de bacias hidrográficas, e isso demonstra o quanto eles são importantes (GEORGIN; OLIVEIRA; DA ROSA, 2015). A 


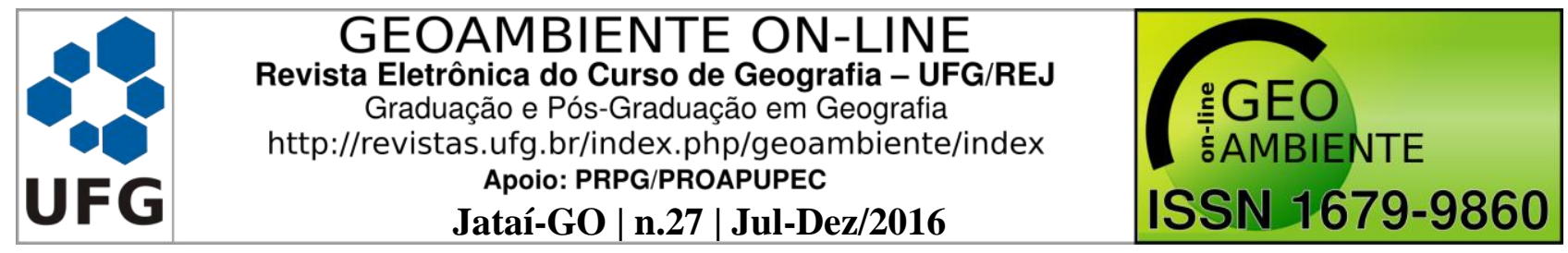

morfometria de uma bacia hidrográfica é uma ferramenta essencial de diagnóstico da susceptibilidade à degradação ambiental. Retrata a disposição, o tamanho e a forma do percurso de cada segmento de rio e a densidade, e o modo de distribuição de toda a rede de drenagem do terreno (STRAHLER, 1957, apud ZANATA et al, 2011).

A determinação de vários parâmetros de uma bacia fornece informações que são úteis na tomada de decisão de como manejar essa bacia,além de simplesmente descrevê-la. As variáveis morfométricas podem ser úteis em projetos ou planejamentos ambientais futuros envolvendo o local estudado (GUERRA, 1995; CAMPOS et al., 2015).

A fim de empreender uma análise morfométrica destinada ao planejamento de uso dos recursos naturais, desenvolveu-se este trabalho na microbacia hidrográfica do Córrego Manoel João (MCMJ), localizada nos municípios de Porto Nacional e Brejinho de Nazaré, Estado do Tocantins.

A escolha da microbacia se deu diante do objetivo de tornar a área alvo de desenvolvimento de estudos e pesquisas acadêmicas, mas principalmente pela inexistência de dados e informações técnicas a respeito da bacia, que são de interesse a gestores, usuários, e comunidade local em geral, quando se trata do manejo da MCMJ.

O objetivo do estudo foi portanto, obter e analisar as características morfométricas da Microbacia Hidrográfica do Córrego Manoel João, visando compreender sua dinâmica e suas principais características, além de gerar dados que possam vir a ser úteis na gestão dos recursos hídricos e os recursos naturais locais.

\section{Material e Métodos}

\section{Área de estudo}

A MCMJ constitui-se em uma sub-bacia hidrográfica do Córrego Titira, sub-bacia do Córrego Ribeirão do Carmo, por sua vez sub-bacia do Rio Tocantins. A MCMJ situa-se entre as latitudes Sul de $10^{\circ} 45^{\prime} 0^{\prime \prime}$ e $11^{\circ} 0$ '0" e os longitudes Oeste de $48^{\circ} 30^{\prime} 0^{\prime \prime}$ e $48^{\circ} 45^{\prime}$ 0", com $90 \%$ de sua área no município de Porto Nacional e 10\% em Brejinho de Nazaré (

Figura 1).

A MCMJ está inserida em uma região que possui precipitação média anual entre 1700 $\mathrm{mm}$ e $1800 \mathrm{~mm}$ e temperatura média anual do ar entre $26^{\circ} \mathrm{C}$ e $27^{\circ} \mathrm{C}$. Segundo a regionalização climática de Thornthwaite, o clima predominante na região é C2Wa'a', - Clima úmido subúmido com moderada deficiência hídrica no inverno, evapotranspiração potencial média 


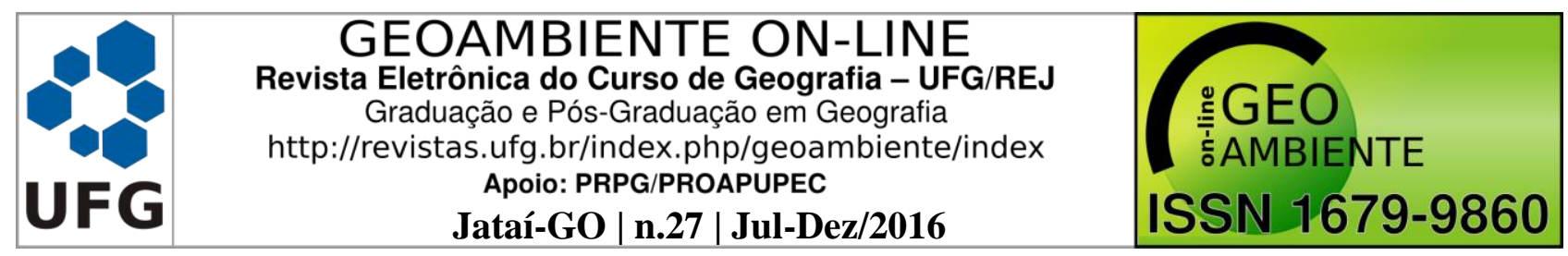

anual de $1.500 \mathrm{~mm}$, distribuindo-se no verão em torno de $420 \mathrm{~mm}$ ao longo dos três meses consecutivos com temperatura mais elevada (SOUZA; BORGES; DIAS, 2012).

Figura 1. Mapa de localização da MCMJ

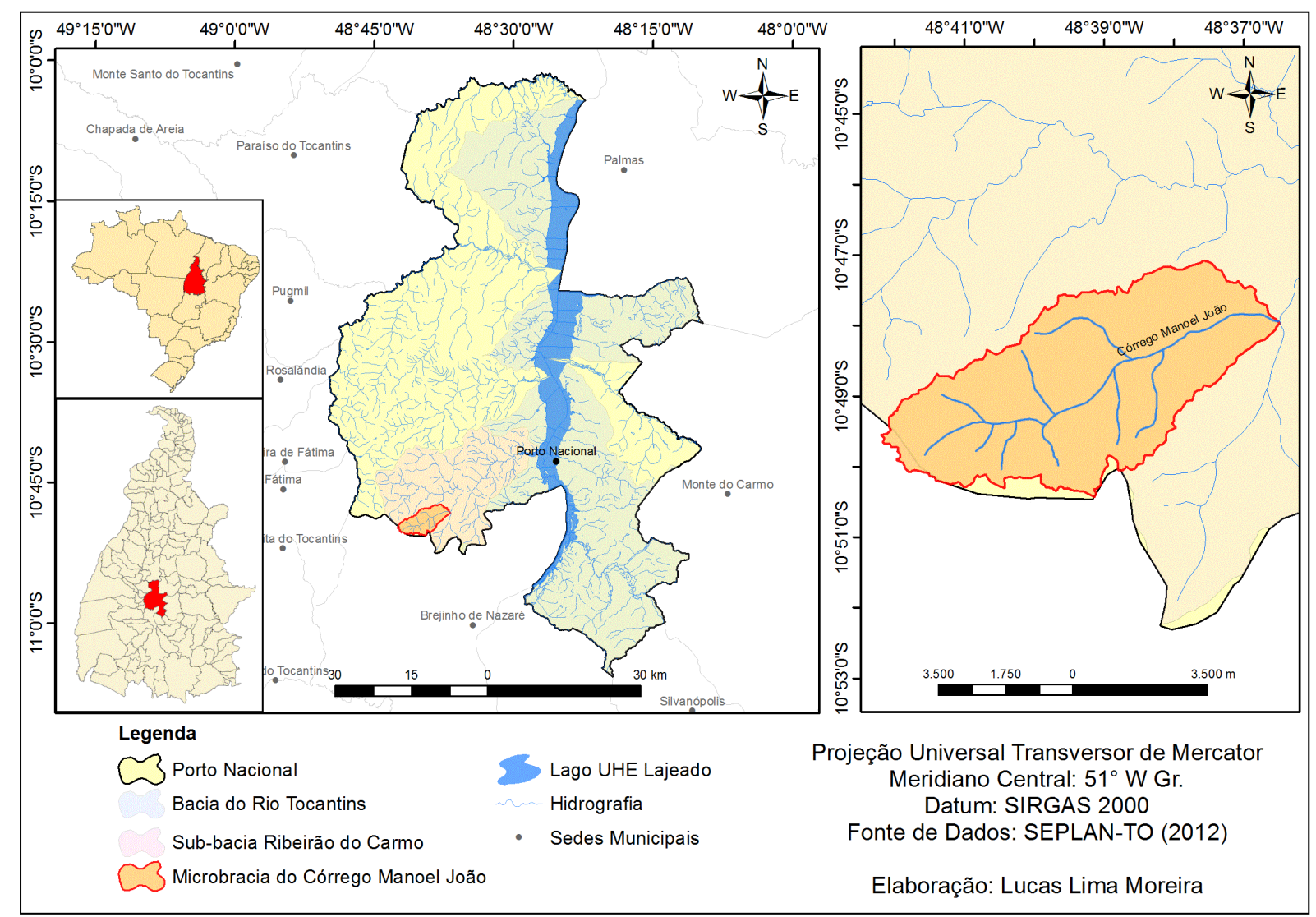

A geologia da microbacia é composta por embasamento cristalino da suíte Matança (granito, álcali-granito, granito pórfiro e granitoides). Nas partes mais altas da microbacia (divisores de água) ocorrem rochas da Formação Pimenteiras - argilitos e siltitos com intercalações de arenito ferruginoso e lentes de conglomerado basal (CPRM, 2004). Os solos predominantes na região são latossolos e cambissolos (SEPLAN, 2012).

Quanto ao uso e ocupação do solo a MCMJ apresenta 25,59\% de áreas antrópicas (capoeira, culturas permanentes, culturas temporárias e pastagem), $0,18 \%$ edificações, $48,21 \%$ de formações de cerrado, 25,27\%de formações florestais, $0,02 \%$ de corpos d'água e $0,73 \%$ deafloramentos rochosos (SANTOS, 2015).

\section{Método}

Para delimitação da MCMJ analisou-se comparativamente, no Google Earth, a delimi- 


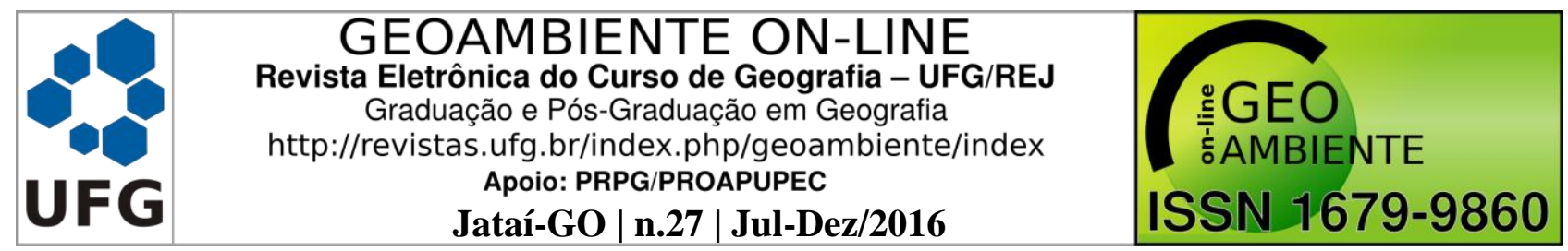

tação de Santos (2015) com a delimitação automática gerada por meio do MDE do projeto TOPODATA. A delimitação automática foi realizada por meio da ferramenta ArcHydro no software ArcGIS. As delimitações mostraram-se bastante semelhantes, no entanto optou-se pela combinação das duas delimitações para maior veracidadeao relevo da microbacia.

Para obtenção dos canais de drenagem analisou-se comparativamente, no software Google Earth,os canais vetorizados no próprio Google Earth, em escala aproximada de 1:10.000 com os canais gerados automaticamente via MDE do projeto TOPODATA, no software ArcGIS, e com a hidrografia da Base Cartográfica Digital disponibilizada pela Secretaria do Planejamento do Tocantins (Seplan/TO).

Por meio de fotointerpretação, verificou-se que os canais vetorizados sobre a imagem do Google Earth caracterizaram-se mais fiéis à realidade da imagem, nos quais se realizou alguns ajustes com base nas outras duas hidrografias. Gerou-se um mapa de canais bastante fiel a realidade da MCMJ, o qual passou a ser adotado na análise morfométrica (Figura 2).

Figura 2. Delimitação e hidrografia da MCMJ

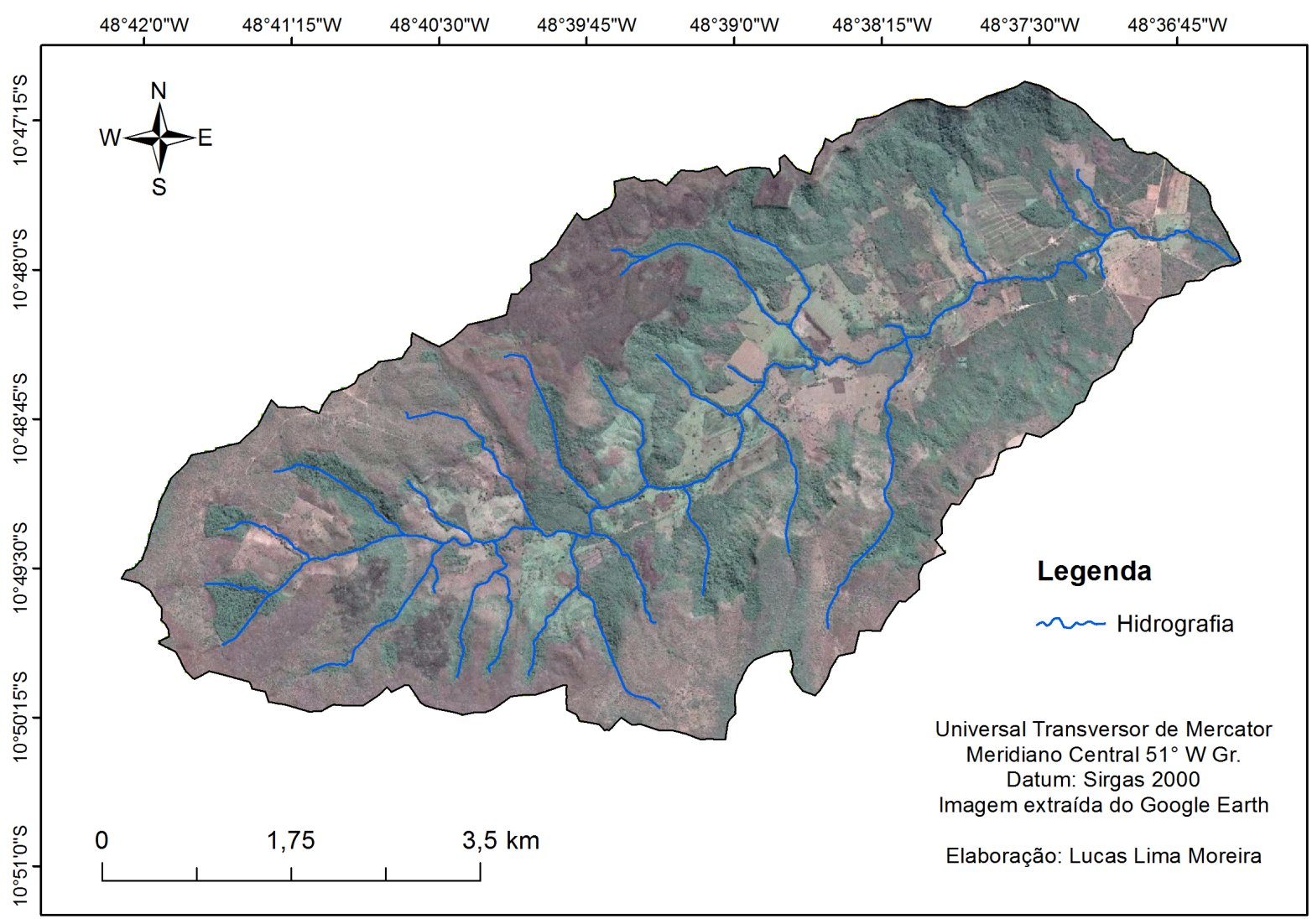

A morfometria da MCMJ foi realizada com base nos parâmetros e índices compilados por Christofoletti (1980), que os abordou em quatro grupos: hierarquia fluvial, análise areal, 
análise linear e análise hipsométrica, conforme Tabela 1.

Tabela 1. Parâmetros morfométricos para análise da MCMJ

\begin{tabular}{|c|c|c|c|}
\hline Grupo & Parâmetro & Definição & Equação \\
\hline Hierarquia Fluvial & Ordem da bacia & $\begin{array}{l}\text { Os canais sem tributários são os de } 1^{\mathrm{a}} \text { ordem, os de } 2^{\mathrm{a}} \\
\text { ordem são formados por dois canais de } 1^{\mathrm{a}} \text { ordem, e só } \\
\text { recebem afluentes de } 1^{\mathrm{a}} \text { ordem; os canais de } 3^{\mathrm{a}} \text { ordem } \\
\text { surgem da confluência de dois canais de } 2^{\mathrm{a}} \text { ordem, } \\
\text { podendo receber afluentes de } 2^{\mathrm{a}} \text { e de } 1^{\mathrm{a}} \text { ordem, e assim } \\
\text { sucessivamente. Modelo de Strahler }\end{array}$ & \\
\hline \multirow{2}{*}{ Análise linear } & $\begin{array}{l}\text { Comprimento do } \\
\text { rio principal }\end{array}$ & $\begin{array}{l}\text { Curso de água mais longo, da desembocadura da bacia } \\
\text { até determinada nascente, medido como a soma dos } \\
\text { comprimentos dos seus ligamentos. }\end{array}$ & --- \\
\hline & $\begin{array}{l}\text { Gradiente de } \\
\text { Canais }(\mathrm{Gc})\end{array}$ & $\begin{array}{l}\text { Relação entre a amplitude altimétrica do canal (Hc) e o } \\
\text { comprimento do canal (L) expresso em porcentagem. }\end{array}$ & $\mathrm{Gc}=\frac{\mathrm{Hc}}{\mathrm{L}}$ \\
\hline \multirow{5}{*}{ Análise areal } & Área da bacia (A) & $\begin{array}{l}\text { É toda a área drenada pelo conjunto do sistema fluvial, } \\
\text { projetada em plano horizontal. }\end{array}$ & --- \\
\hline & $\begin{array}{l}\text { Índice de circula- } \\
\quad \text { ridade }(\mathrm{Ic})\end{array}$ & $\begin{array}{l}\text { Relação entre a área da bacia }(\mathrm{A}) \text { e a área do círculo de } \\
\text { perímetro igual ao da bacia }(\mathrm{Ac}) \text {. }\end{array}$ & $\mathrm{Ic}=\frac{\mathrm{A}}{\mathrm{Ac}}$ \\
\hline & $\begin{array}{l}\text { Densidade de rios } \\
\text { (Dr) }\end{array}$ & $\begin{array}{l}\text { Relação existente entre o número de canais }(\mathrm{N}) \text { e a área } \\
\text { da bacia }(\mathrm{A}) \text {. }\end{array}$ & $\mathrm{Dh}=\frac{\mathrm{N}}{\mathrm{A}}$ \\
\hline & $\begin{array}{l}\text { Densidade de } \\
\text { drenagem }(\mathrm{Dd})\end{array}$ & $\begin{array}{l}\text { Correlaciona o comprimento total dos canais de esco- } \\
\text { amento }(\mathrm{Lt}) \text { com a área da bacia hidrográfica }(\mathrm{A}) \text {. }\end{array}$ & $\mathrm{Dd}=\frac{\mathrm{Lt}}{\mathrm{A}}$ \\
\hline & $\begin{array}{c}\text { Coeficiente de } \\
\text { Manutenção }(\mathrm{Cm})\end{array}$ & $\begin{array}{l}\text { Fornece a área mínima necessária para a manutenção } \\
\text { de um metro de canal de escoamento. }\end{array}$ & $\mathrm{Cm}=\frac{1}{\mathrm{Dd}} \cdot 1000$ \\
\hline \multirow{2}{*}{$\begin{array}{l}\text { Análise Hipsomé- } \\
\text { trica }\end{array}$} & $\begin{array}{l}\text { Amplitude altimé- } \\
\text { trica máxima } \\
(\mathrm{Hm})\end{array}$ & $\begin{array}{l}\text { Diferença altimétrica, em metros, entre a altitude da } \\
\text { desembocadura e a altitude do ponto mais alto no divi- } \\
\text { sor de águas. }\end{array}$ & $\begin{aligned} \mathrm{Hm}= & \mathrm{a} \max -\mathrm{a} \\
& \min \end{aligned}$ \\
\hline & $\begin{array}{l}\text { Relação de relevo } \\
(\mathrm{Rr})\end{array}$ & $\begin{array}{l}\text { Relação existente entre a amplitude altimétrica máxima } \\
(\mathrm{Hm}) \text { e o comprimento do canal principal (L). }\end{array}$ & $\mathrm{Rr}=\frac{\mathrm{Hm}}{\mathrm{L}}$ \\
\hline
\end{tabular}

Fonte:Elaborado a partir de Christofoletti (1980).

Conforme sugere Christofoletti (1980), a análise morfométrica da MCMJ iniciou-se pela ordenação dos canais fluviais, com a finalidade de estabelecer a hierarquia fluvial. A partir de então, processou-se a análise dos aspectos lineares, areais e hipsométricos, usando os softwares ArcGIS 10.1.2 e Microsoft Excel 2010.

Os valores altimétricos e de declividade foram obtidos por meio do MDE da microbacia no ArcGIS. A declividade foi classificada conforme Embrapa (1979).

\section{Resultados e Discussão}

Os dados climatológicos recentes do Serviço Geológico do Brasil (estação climatoló- 


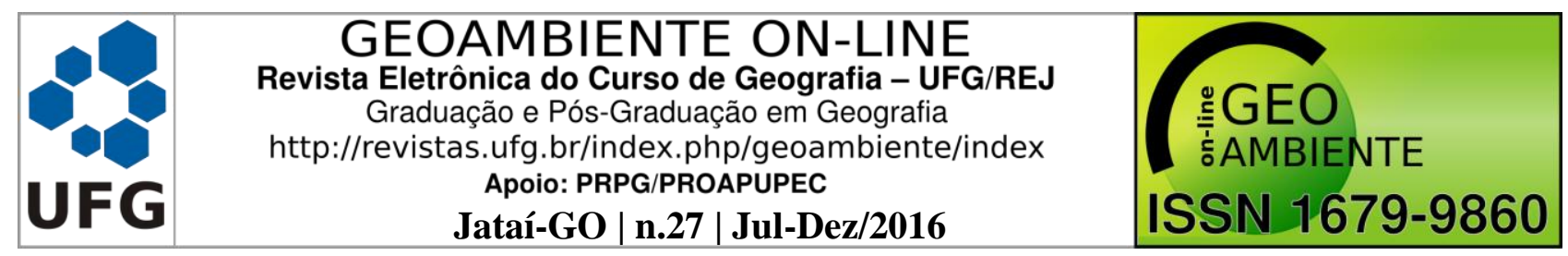

gica de Porto Nacional) mostram o comportamento do clima na região,segundo a Figura 3.

Figura 3. Dados climatológicos de Porto Nacional (2006-2010).

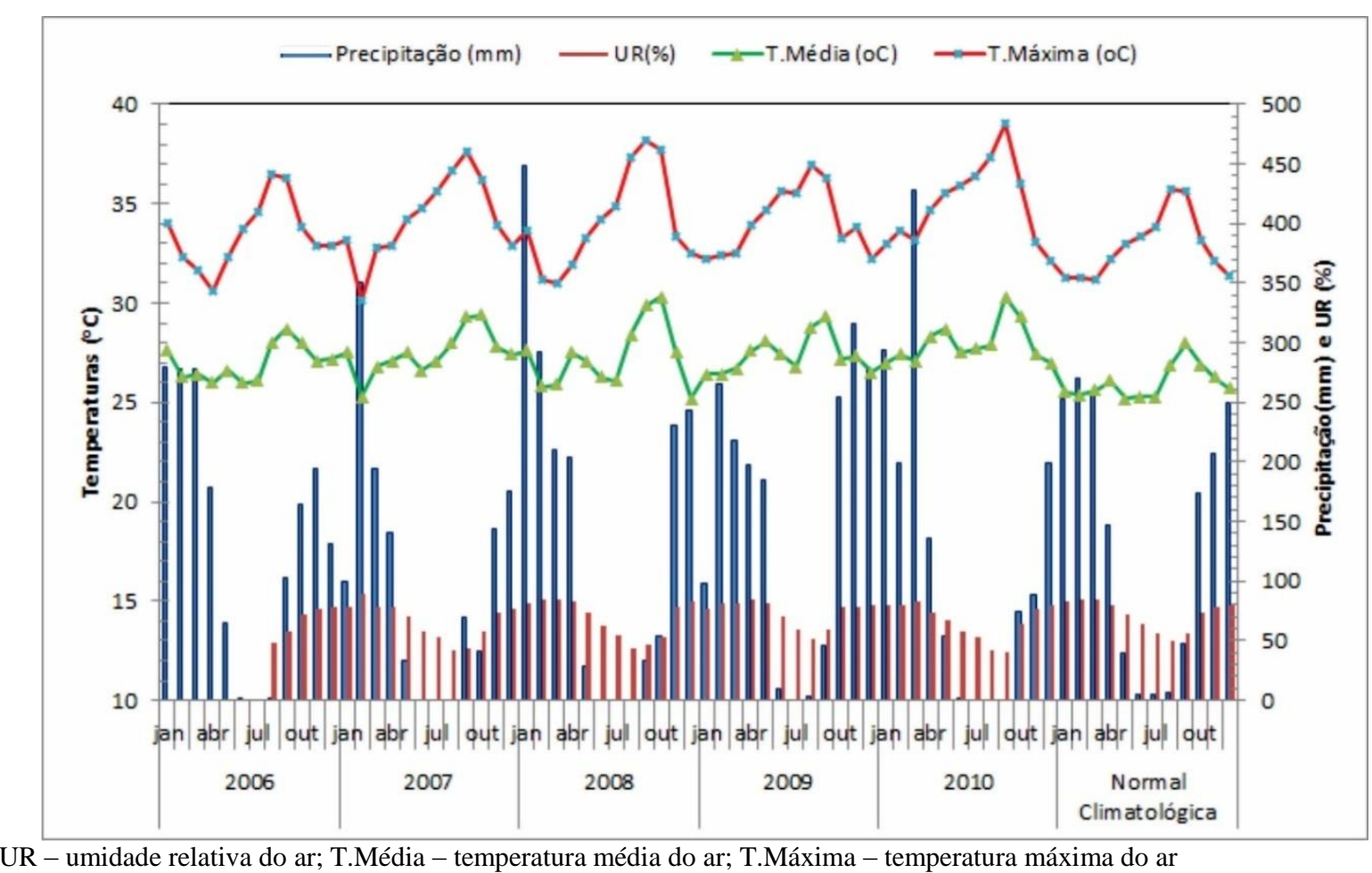

Fonte: Elaborado a partir de CPRM (2011).

Nota-se observando a Figura 4, que nos últimos três anos, a precipitação mensal e total anual oscila entre 1.215 a 2.249,5 mm/ano. O ano 2013 foi um ano atípico, com o total anual muito acima da normal climatológica ao passo que os demais anos tiveram comportamento normal. As consequiências diretas dessa pluviosidade foram instauração de novos processos de erosão hídrica superficial com perdas de solos e cheias/inundações.

As Tabelas 2 e 3 apresentam os dados obtidos para o cálculo dos parâmetros morfométricos propriamente ditos. Segundo Christofoletti (1980), o número total de canais (N), pela ordenação de Strahler, é o número de canais de primeira ordem, de forma que a MCMJ possui 29 canais (Tabela 2 ).

A MCMJ possui hierarquia fluvial de $3^{\mathrm{a}}$ ordem, segundo a classificação de Strahler (1952) - Figura 5. O padrão de drenagem é dendrítico, que é tipicamente desenvolvido sobre rochas de resistência uniforme, ou em estruturas sedimentares horizontais. 
Figura 4. Distribuição da precipitação pluviométrica Porto Nacional (2013-2015).

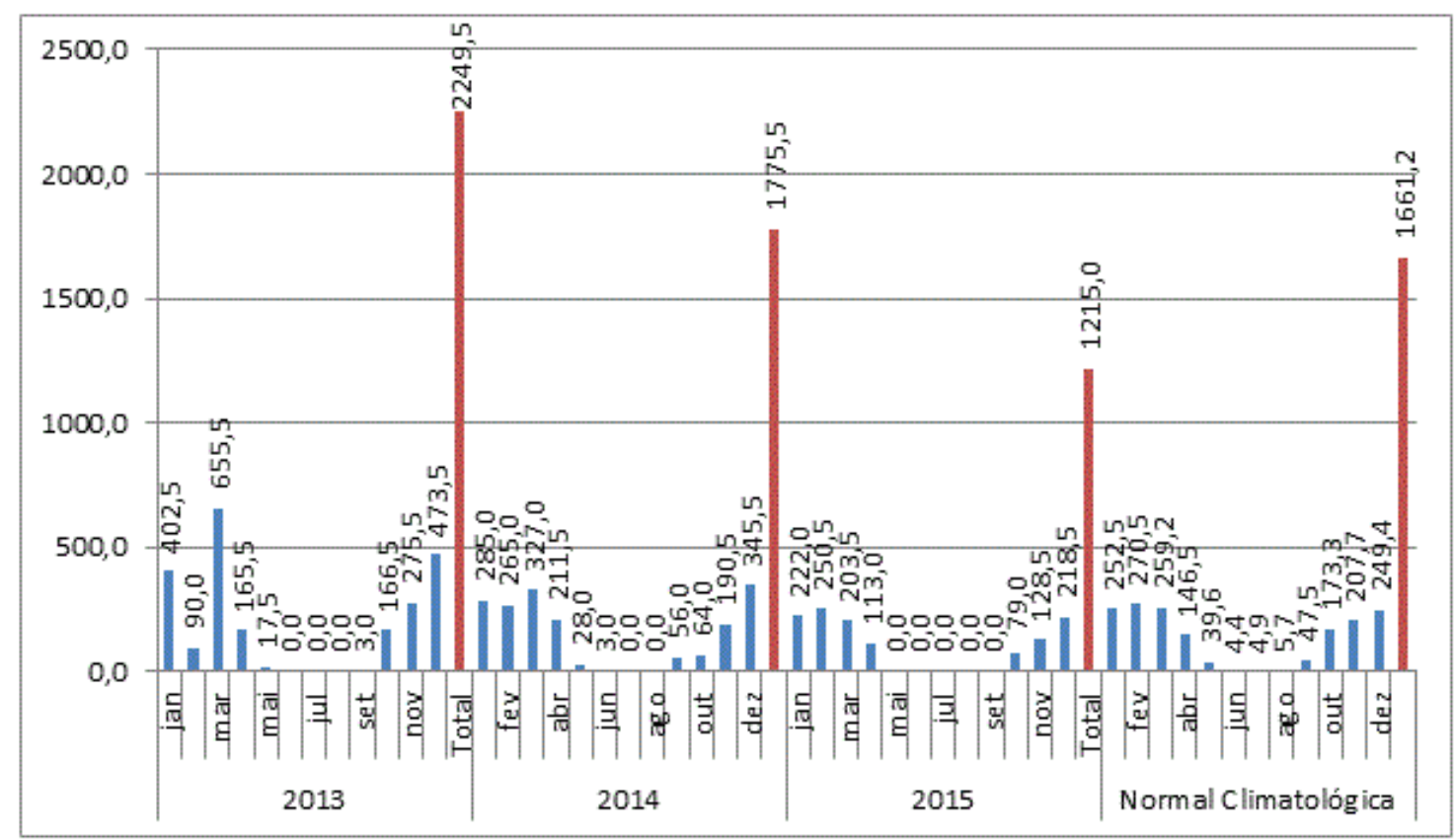

Fonte: Fazenda AGRO 3MIL (Dados 2013-2015)

Tabela 2. Quantidade de canais da MCMJ

\begin{tabular}{cc}
\hline Ordem & $\mathbf{N}^{\mathbf{0}}$ de canais \\
\hline $1^{\mathrm{a}}$ & 29 \\
$2^{\mathrm{a}}$ & 6 \\
$3^{\mathrm{a}}$ & 1 \\
\hline
\end{tabular}

Tabela 3. Dados básicos para o cálculo dos parâmetros morfométricos.

\begin{tabular}{ll}
\hline Dados & Valor \\
\hline Perímetro & $29,66 \mathrm{~km}$ \\
Comprimento total dos canais (Lt) & $44,98 \mathrm{~km}$ \\
Número de canais (N) & 29 \\
Altitude máxima (Amax) & $598 \mathrm{~m}$ \\
Altitude mínima (Amin) & $277,22 \mathrm{~m}$ \\
Declividade média (H) & $14,22 \%$ \\
\hline
\end{tabular}




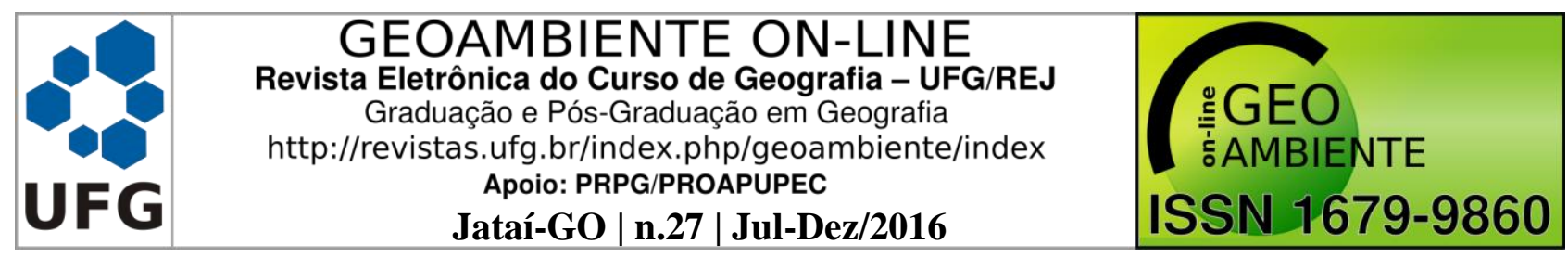

Figura 5. Hierarquia fluvial da MCMJ

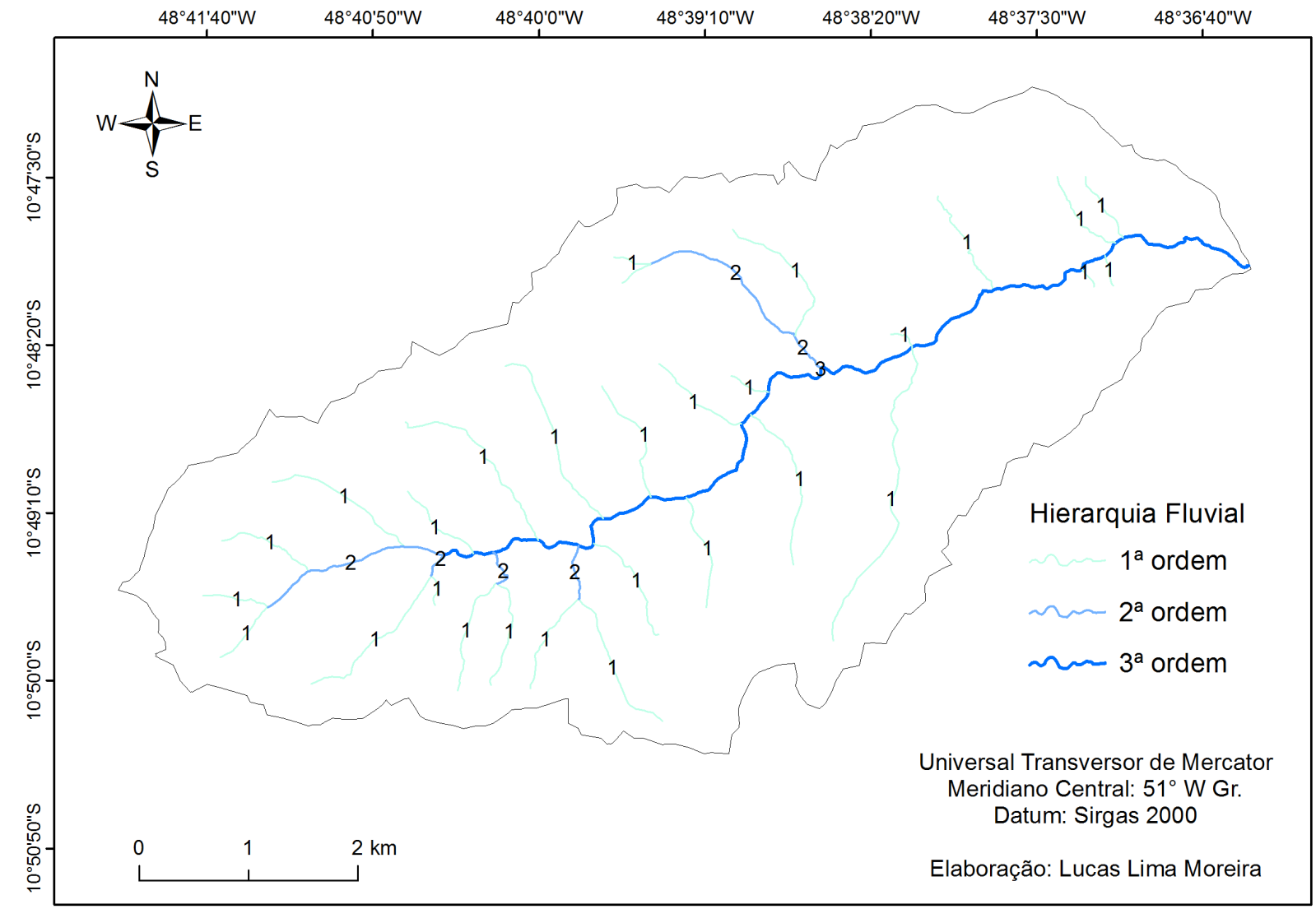

A MCMJ é aderente ao conceito de Calijuri e Bubel (2006), que definiram uma microbacia como sendo, bacia hidrográfica formada por canais de até $3^{\text {a }}$ ordem e áreas sensíveis a perturbações (Tabela 4). Para Tonello et al. (2006), redes de drenagem de até $4^{\mathrm{a}}$ ordem são comuns em pequenas bacias e refletem os efeitos diretos de como a terra é utilizada. No caso específico da MCMJ o uso da terra ainda é pouco expressivo, pois Santos (2015) revela que $73,48 \%$ da área desta microbacia são de vegetação primitiva (cerrado e floresta) e $25,77 \%$ de usos antrópicos (capoeira, lavoura permanente, lavoura temporária, pastagem e edificações.), no entanto as matas ciliares vêm sofrendo redução, cedendo lugar para as pastagens cultivadas para a pecuária de corte (animais de grande porte).

Segundo Santos (2015) as matas ciliares representam 3,37\% da área da bacia, e estão em maior extensão ao longo do Córrego Manoel João - fundo de vale aberto -, e seus trechos mais conservados estão no alto da microbacia, nas cabeceiras dos cursos d'água formadores do Córrego Manoel João. Santos (2015) revela também que nos tributários do Córrego Manoel João, a mata ciliar não mostra sinais ou evidências de inundação, ao passo que ao longo do canal deste córrego são comuns áreas inundáveis. Assim, as matas ciliares exibem formações não inundáveis e inundáveis. 


\begin{tabular}{|c|c|c|}
\hline UF & 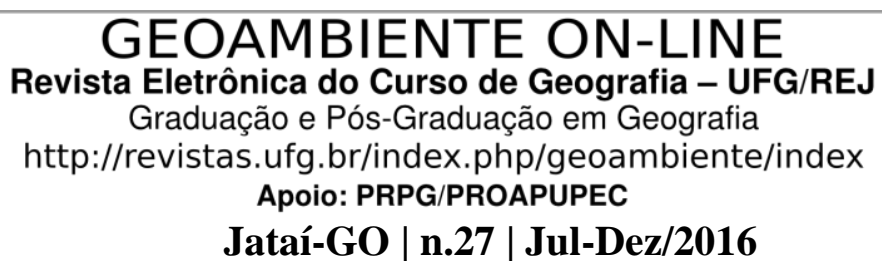 & $\begin{array}{l}\text { @GEO } \\
\text { ISSN } 1679-9860\end{array}$ \\
\hline
\end{tabular}

Tabela 4. Parâmetros morfométricos MCMJ

\begin{tabular}{lll}
\hline Grupo & Parâmetros & Valor \\
\hline Hierarquia Fluvial & Ordem & $3^{\mathrm{a}}$ \\
\hline \multirow{2}{*}{ Análise Linear } & Comprimento do rio principal & $12 \mathrm{~km}$ \\
& Gradiente de canais (Gc) & $0,02 \%$ \\
\hline \multirow{3}{*}{ Análise Areal } & Área da bacia (A) & $34,43 \mathrm{~km}^{2}$ \\
& Índice de circularidade (Ic) & 0,49 \\
& Densidade de rios (Dr) & 0,842 canais $/ \mathrm{km}^{2}$ \\
& Densidade de drenagem (Dd) & $1,31 \mathrm{~km} / \mathrm{km}^{2}$ \\
& Coeficiente de Manutenção (Cm) & $765,53 \mathrm{~m} / \mathrm{m}$ \\
\hline \multirow{2}{*}{ Análise Hipsométrica } & Amplitude altimétrica máxima $(\mathrm{Hm})$ & $320,78 \mathrm{~m}$ \\
& Relação de relevo (Rr) & 0,03
\end{tabular}

A MCMJ possui uma área de $34,43 \mathrm{~km}^{2}$, confirmando assim sua classificação como microbacia, por apresentar área inferior a $100 \mathrm{~km}^{2}$ (FAUSTINO, 1996).

O gradiente de canais (Gc) indica a declividade dos cursos d'água (CHRISTOFOLETTI, 1980). O valor obtido para o Córrego Manoel João (0,02\%) demonstrando uma baixa declividade, visto que o mesmo possui $12 \mathrm{~km}$ de extensão.

A relação de relevo (Rr) da MCMJ (0,03), conforme a classificação de Piedade (1980), enquadra-se como baixa, por estar entre 0,00 e 0,10. Os dois parâmetros demonstram um baixo declive do canal principal do Córrego Manoel João, o que reduz a velocidade do escoamento superficial em maior parte de sua extensão, e consequentemente a sua capacidade de provocar erosão.

O índice de circularidade (Ic) é de 0,49. De acordo com a classificação de Schum (1956), por ser menor que 0,51,o índice indica uma forma alongada da microbacia, o que reduz o tempo de concentração das águas e consequentemente a probabilidade de ocorrências de cheias, em condições normais de precipitação.

A densidade de rios (Dr), ou densidade hidrográfica (Dh),é de 0,842 canais/km². Conforme Christofoletti (1980), sua obtenção é importante por representar a capacidade de uma área em gerar novos cursos de água.A Densidade de drenagem $\left(1,31 \mathrm{~km} / \mathrm{km}^{2}\right)$ é baixa, por ser menor que $7,5 \mathrm{~km} / \mathrm{km}^{2}$, de acordo comChristofoletti (1969 apud COLLARES, 2000). Isto indica que a MCMJ apresenta drenagem pouco desenvolvida (CARDOSO et al., 2006), e com maior superfície de contribuição, fazendo com que o deflúvio demore mais para atingir os rios (GARCEZ, 1974 apud VALLE JUNIOR, 2008). Tal constatação deve-se à combinação dos 


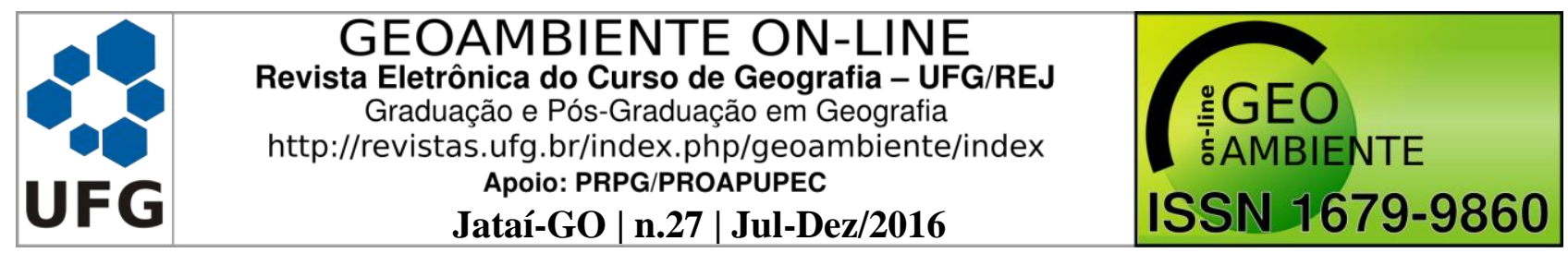

fatores: rochas resistentes à formação de canais, solos pouco permeáveis e existência de densas coberturas vegetais (florestas e cerrado denso).

O coeficiente de manutenção $(\mathrm{Cm})$ obtido para a MCMJ é de $765,53 \mathrm{~m}^{2} / \mathrm{m}$, confirmando juntamente com baixa Dd obtida o pouco desenvolvimento do sistema de drenagem, e o baixo grau de dissecação do relevo, visto a expressiva área necessária para manutenção de um metro de canal de escoamento.

A hipsometria da microbacia é exibida na Figura 6 e verifica-se na Tabela 5 a porcentagem da área de drenagem nas faixas altimétricas definidas. Observa-se que a maior parte da área da microbacia apresenta-se na faixa entre 500 e $598 \mathrm{~m}$ de altitude, correspondendo a $43,87 \%$.

Figura 6. Mapa hipsométrico da MCMJ

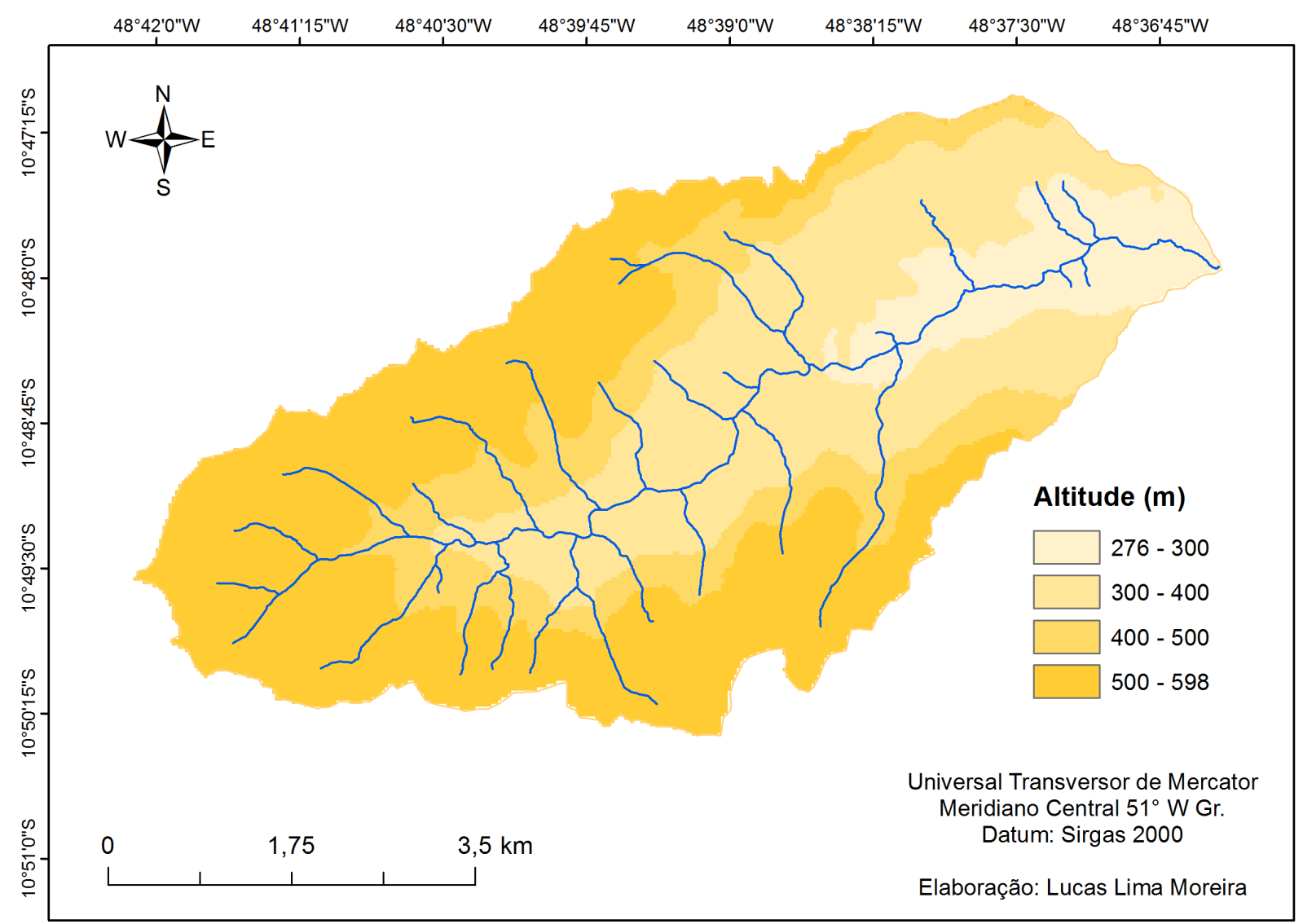


Tabela 5. Distribuição da altitude de acordo com a área da MCMJ

\begin{tabular}{ccc}
\hline Altitude (m) & Área $\left(\mathbf{k m}^{2}\right)$ & \% MCMJ \\
\hline $276-300$ & 3,34 & 9,68 \\
$300-400$ & 10,26 & 29,75 \\
$400-500$ & 5,76 & 16,70 \\
$500-598$ & 15,12 & 43,87 \\
\hline
\end{tabular}

A MCMJ caracteriza-se como sendo formada por cursos d'água jovens, curtos e de alta energia uma vez que os desníveis são elevados - das nascentes até a desembocadura no córrego principal.

A declividade do terreno da microbacia (Figura 7)segundo Cardoso et al. (2006), influencia a relação entre a precipitação e o deflúvio da bacia hidrográfica, sobretudo em relação à velocidade de escoamento superficial, e logo à infiltração de água no solo.

Figura 7. Mapa de declividade da MCMJ

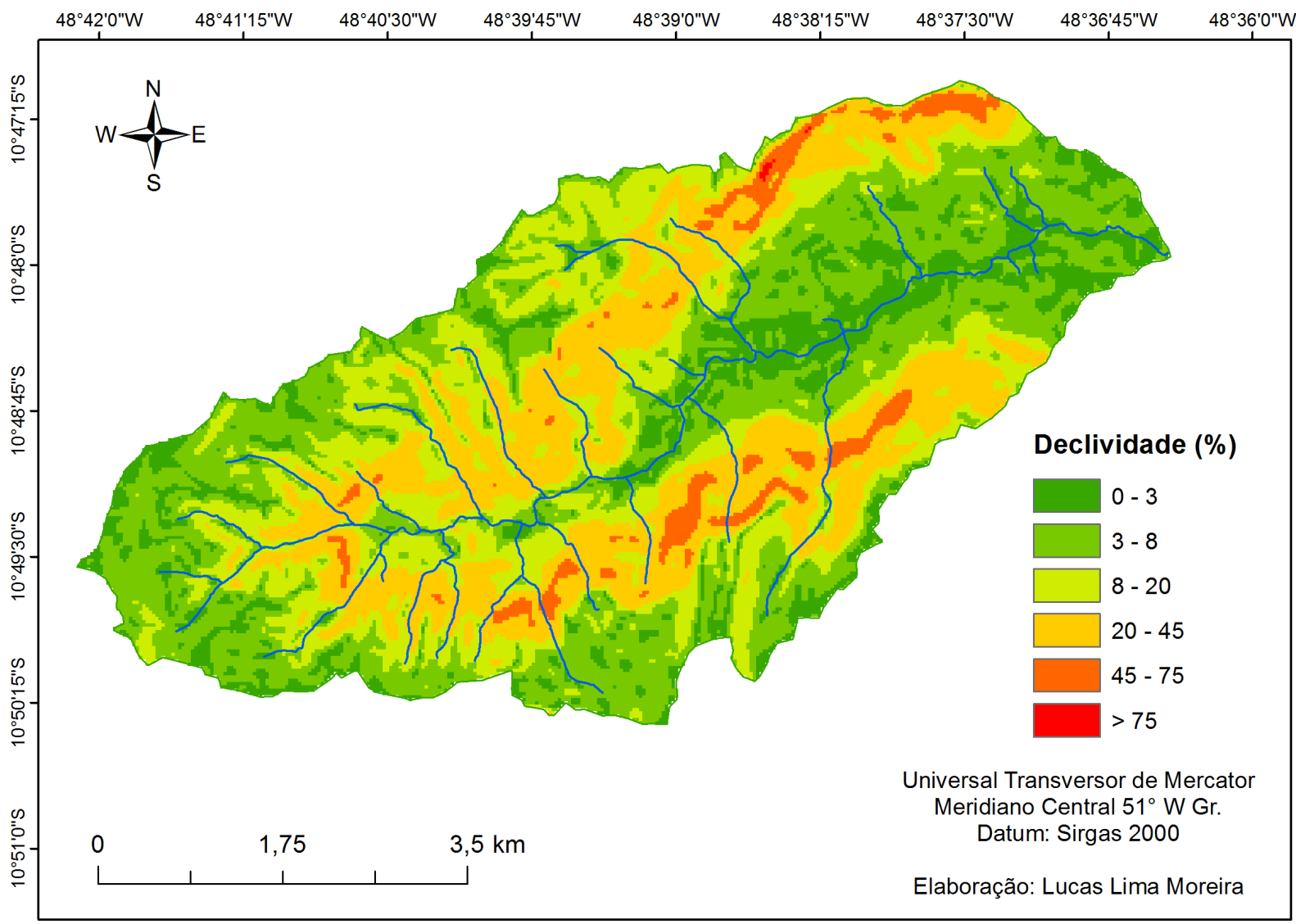




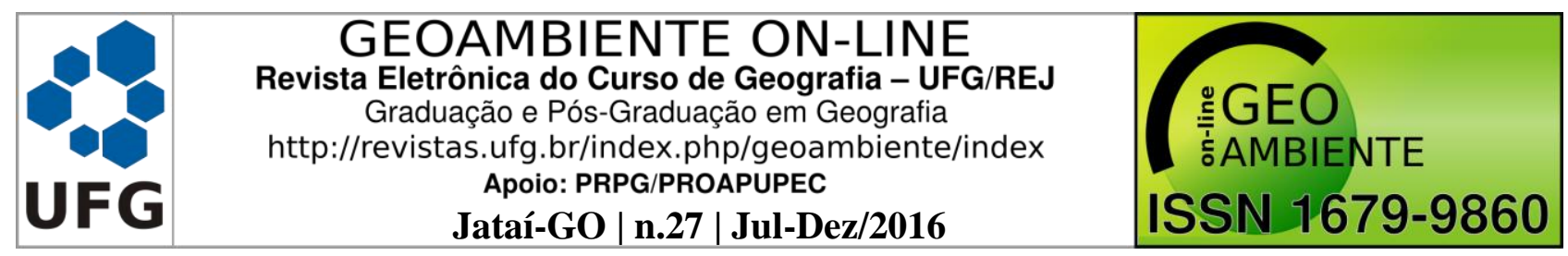

$\mathrm{Na}$ Tabela 6, apresenta-se a classificação da declividade em seis classes e as informações quantitativas associadas, conforme Embrapa (1979).

Tabela 6. Distribuição das classes de declividade da MCMJ

\begin{tabular}{cccc}
\hline Declividade (\%) & Relevo & $\mathbf{k m}^{\mathbf{2}}$ & \% MCMJ \\
\hline $0-3$ & Plano & 4,92 & 14,28 \\
$3-8$ & Suave ondulado & 11,49 & 33,34 \\
$8-20$ & Ondulado & 8,52 & 24,72 \\
$20-45$ & Forte ondulado & 8,37 & 24,29 \\
$45-75$ & Montanhoso & 1,14 & 3,32 \\
$>75$ & Escarpado & 0,013 & 0,04 \\
\hline
\end{tabular}

Observa-se que o relevo suave ondulado juntamente com o relevo plano representam 47,62\% da área total da microbacia, favorecendo o uso agrícola, seja mecanizado ou não. Todavia, as classes mais íngremes de relevo alcançam 52,37\%. Estas áreas representam as áreas com as maiores diferenças de altitude, e onde está a maior parte dos canais de primeira ordem, o que favorece um escoamento superficial mais rápido e indica um maior risco de erosão hídrica, sobretudo em dias de elevada precipitação.

\section{Considerações Finais}

Em condições normais de precipitação, a forma alongada da microbacia caracteriza-a como pouca susceptível à ocorrência de enchentes,e isso representa um menor risco de degradação ambiental, principalmente de perda de solos por erosão hídrica.

A preservação das matas ciliares nos canais de primeira ordem se faz extremamente importante para a redução do risco de processos erosivos e assoreamento do curso do Córrego Manoel João, visto que a maior parte destes canais está inserida em regiões de declive mais acentuado, com escoamento superficial mais rápido.

As parcelas da microbacia com relevo plano e suave ondulado são as mais favoráveis à agricultura, que pode ser intensificada considerando a adoção das práticas conservacionistas para evitar perdas de solos por erosão hídrica. Nas parcelas com maiores declives recomendase, se possível, a manutenção da vegetação primitiva (sobretudo de porte florestal). Todavia, em caso de uso agropecuário com pastagens, florestamento ou lavouras temporárias de subsistência, é indispensável o uso de práticas mecânicas, tais como terraceamentos e sulcos, 


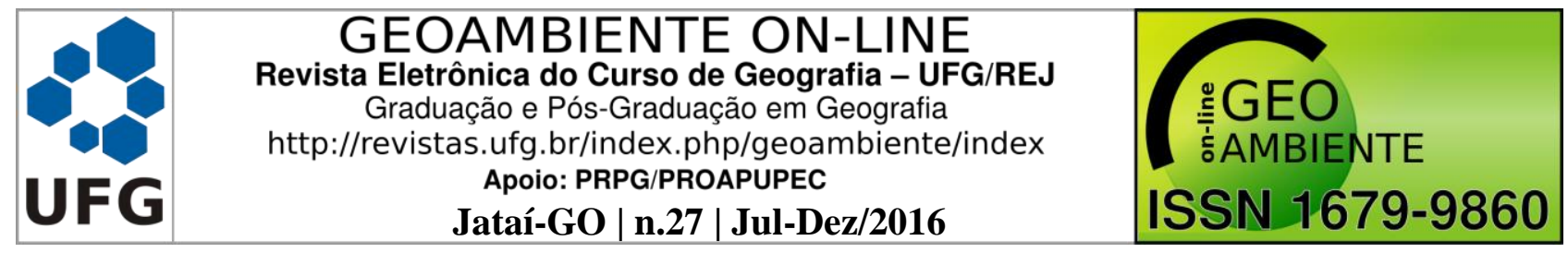

e camaleões, ou práticas conservacionistas vegetativas para redução dos efeitos de erosão e escoamento rápido.

\section{Agradecimentos}

Os autores agradecem as contribuições dos professores Girlene Maciel e Eduardo Quirino, e colegas Erton Moraes e Isac Tavares.

\section{Referências Bibliográficas}

CAMPOS, S.; FELIPE, A. C.;CAMPOS, M.;RECHE, A. M. Geoprocessamento aplicado na caracterização morfométrica da microbacia do ribeirão descalvado-Botucatu, SP. Irriga, v. 1, n. 1, p. 52, 2015.

CALIJURI, M.C.; BUBEL, A.P.M. Conceituação de Microbacias. In:LIMA, W de P.; ZAKIA, M.J.B. (Orgs.) As florestas plantadas e a água.Implementando o conceito da microbacia hidrográfica como unidade deplanejamento. São Carlos: Ed. RiMA, 2006. 226p.

CARDOSO, C. A.; DIAS, H. C. T.; SOARES, B. C. P.; MARTINS, S. V. Caracterização morfométrica da bacia hidrográfica do Rio Debossan, Nova Friburgo-RJ. Revista Árvore. Viçosa-MG, v.30, n.2, p.241-248, 2006.

CHRISTOFOLETTI, Antônio. Geomorfologia. São Paulo: Edgard Blucher, 1980.

COLLARES, E. G. Avaliação de alterações em redes de drenagem de microbacias como subsídio ao zoneamento geoambiental de bacias hidrográficas: aplicação na bacia hidrográfica do rio Capivari-SP. Tese de Doutorado - Escola de Engenharia de São Carlos. Universidade de São Paulo. 194p. 2000.

COSTA, S. B.; PASSOS, M. M.; SOUZA FILHO, E. E. A análise morfométrica da bacia hidrográfica do córrego Água da Marilena: uma contribuição para à gestão ambiental das bacias hidrográficas do extremo noroeste do estado do Paraná. Revista Geonorte, v. 5, n. 23, p. 1-6, 2016.

CPRM - SERVIÇO GEOLÓGICO DO BRASIL (Org.). Carta Geológica do Brasil ao Milionésimo: $\quad 2004.2$ Docantins. <http://rigeo.cprm.gov.br/xmlui/handle/doc/4983>. Acesso em: 12 fev. 2016.

DPZE, Diretoria de Pesquisa e Zoneamento Ecológico-Econômico (Org.). Perfil Socioeconômico dos municípios do Tocantins. Porto Nacional: Seplan, 2013.

EMPRESA BRASILEIRA DE PESQUISAAGROPECUÁRIA - EMBRAPA. Serviço Nacionalde Levantamento e Conservação de Solos (Rio deJaneiro, RJ). In: reunião técnica 


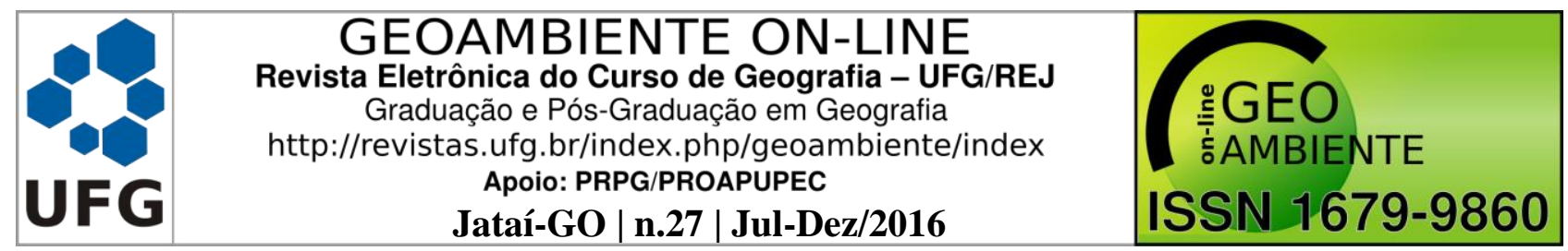

delevantamento de solos, 10.1979, Rio de Janeiro. Súmula... Rio de Janeiro,1979. 83 p. (EMBRAPA-SNLCS. Micelânea, 1).

FAUSTINO, J. Planificación y gestión de manejo de cuencas. Turrialba:CATIE, 1996. 90p. FRANCO, A. C. V.; DAL SANTO, M. A.Contribuição da morfometria para o estudo das inundações na sub-bacia do rio Luís Alves/SC. Mercator (Fortaleza), v. 14, n. 3, p. 151-167, 2015.

GEORGIN, J.; OLIVEIRA, G. A.; DA ROSA, A. L. D. Estudo comparativo de índices morfométricos relacionado com cheias nas bacias hidrográficas do alto Jacuí e VacacaíVacacaí Mirim-RS. Revista Eletrônica em Gestão, Educação e Tecnologia Ambiental, v. 19, n. 2, p. 1357-1364, 2015.

GUERRA, A. J.T. Processos erosivos nas encostas. In:GUERRA, A. J.T. \& CUNHA, S.B., organizadores.Geomorfologia: uma atualização de base e conceitos. Rio deJaneiro, Bertrand Brasil, 1995. 2a ed. p. 149-209.

HORTON, R.E. Erosional development of streams and their drainage basins: hidrophysical approach to quantitative morphology. Bulletin of the Geological Society of America. 56:275-370, 1945.

INPE (Org.). TOPODATA: Banco de Dados Geomorfométricos do Brasil. Disponível em: <http://www.dsr.inpe.br/topodata/index.php>. Acesso em: 16 jun. 2015.

LORENZON, A. S.; FRAGA, M. de S.; MOREIRA, A. R.; ULIANA, E. M.; SILVA, D. D. da; RIBEIRO, C. A. A. S.; BORGES, A. C. Influência das características morfométricas da bacia hidrográfica do RioBenevente nas enchentes no município de Alfredo Chaves-ES. Revista Ambiente \& Água, v. 10, n. 1, p. 195, 2015.

MACHADO, R. A. S.; LOBÃO, J. S. B.; VAlE, R. M. C.; SOUZA, A. P. M. J Análise morfométrica de bacias hidrográficas como suporte a definição e elaboração de indicadores para a gestão ambiental a partir do uso degeotecnologias. In: XV SIMPÓSIO BRASILEIRO DE SENSORIAMENTO REMOTO, 15., 2011, Curitiba. Anais XV Simpósio Brasileiro de Sensoriamento Remoto.Curitiba: Inpe, 2011. p. 1441 - 1448.

NARDINI, R. C.; CAMPOS, S.; GOMES, L. N.; RIBEIRO, F. L.; PISSARRA, T. C. T.; CAMPOS, M. Técnicas de geoprocessamento para análise morfométrica da microbacia do Ribeirão Alto Água Fria-Bofete (SP). Revista Brasileira de Engenharia de Biossistemas, v. 10, n. 2, p. 170-180, 2016. 
ROCHA, R. M.; LUCAS, A. A. T.; ALMEIDA, C. A. P.; NETO, E. L. M.; NETTO, A. O.

Caracterização morfométrica da sub-bacia do rio Poxim-Açu, Sergipe, Brasil. Revista Ambiente \& Água, v. 9, n. 2, p. 276, 2014.

RUFO, R. L. T.; CRISTO, S. S. V.D. Sensoriamento remoto aplicado na análise do uso e ocupação da bacia hidrográfica do Córrego Titira, Porto nacional, Tocantins. Revista Interface (Porto Nacional), n. 07, 2014.

SANTOS, H. G.D.; ZARONI, M. J. Latossolos. Disponível em: <https://www.agencia.cnptia.embrapa.br/gestor/solos_tropicais/arvore/CONTAG01_11_2212 200611540.html>. Acesso em: 19 fev. 2016.

SANTOS, T. T.D. Análise multitemporal da cobertura e uso da terra na microbacia do Córrego Manoel João - Porto Nacional / Brejinho de Nazaré (TO). 2015. 44 f. TCC (Graduação) - Curso de Engenharia Ambiental, Universidade Federal do Tocantins, Palmas, 2015.

SCHUMM, S. A. Evolution of drainage systems and slopes in badlands of Perth Amboy. Geological Society of America Bulletin, v.67, n.5, p.597-646, 1956.

SILVA, J. L.; TONELLO, K. C.Morfometria da bacia hidrográfica do Ribeirão dos Pinheirinhos, Brotas-SP. Irriga, v. 19, n. 1, p. 103, 2014.

SOUZA, P. A. B.D.; BORGES, R. S. T.; DIAS, R. R. (Org.). Atlas do Tocantins: subsídios ao planejamento da gestão territorial.6 ed. Palmas: Seplan, 2012.

STRAHLER, A.N. Hypsometric analysis of erosional topography. Bulletin of the Geological Society of America, 63:111-1141, 1952.

TOCANTINS.SEPLAN. (Org.). Base Cartográfica Digital Contínua. Disponível em: $<$ http://seplan.to.gov.br/zoneamento/bases-vetoriais/base-cartografica-digital-continua/> .

Acesso em: 17 jan. 2016.

TONELLO, K. C.;DIAS, H. C. T.; SOUZA, A. L.; RIBEIRO, C. A. A. S.; LEITE, F. P. Morfometria da bacia hidrográfica da Cachoeira das Pombas, Guanhães - MG. Revista Árvore, Viçosa, v. 30, n. 5, Out.2006.

VALLE JUNIOR, R. F.D.Diagnóstico de áreas de risco de erosão e conflito de uso dos solos na bacia do rio Uberaba. 2008. 233 f. Tese (Doutorado) - Curso de Agronomia (produção Vegetal), Faculdade de Ciências Agrárias e Veterinárias - Unesp, Jaboticabal, 2008.

ZANATA, M.;PISSARRA, T. C. T.; ARRAES, C. L.; RODRIGUES F. M.; CAMPOS, S. Influência da escala na análise morfométrica de microbacias hidrográficas. Revista Brasileira de Engenharia Agrícola e Ambiental. Campina Grande, v. 15, n. 10, p.1062-1067, 2011. 